Dokuz Eylül Üniversitesi-Mühendislik Fakültesi

Fen ve Mühendislik Dergisi

Cilt 20, Sayı 58, Ocak, 2018
Dokuz Eylul University-Faculty of Engineering Journal of Science and Engineering Volume 20, Issue 58, January, 2018

DOI: $10.21205 /$ deufmd. 2018205811

\title{
Elektromanyetik Ölçümlerinde Kullanılan Radyofrekans Yansıtmasız Kutu Tasarım ve Uygulaması
}

\author{
Şebnem SEÇKIN UĞURLU ${ }^{* 1}$, Ahmet ÖZKURT ${ }^{2}$ \\ ${ }^{1}$ Dokuz Eylül Üniversitesi, Fen Bilimleri Enstitüsü, 35390, İzmir (ORCID:0000-0002- \\ 1153-1072) \\ ${ }^{2}$ Dokuz Eylül Üniversitesi, Mühendislik Fakültesi, Elektrik-Elektronik Mühendisliği \\ Bölümü, 35390, İzmir (ORCID: 0000-0001-6404-7244)
}

(Alınış / Received: 18.04.2017, Kabul / Accepted: 28.09.2017, Online Yayınlanma / Published Online: 20.01.2018)

Anahtar Kelimeler Elektromanyetik

Kalkanlama

Etkinliği,

Yansitmasız Oda

Yüksek Frekans

Benzetim

Özet: Elektromanyetik devre, anten parametreleri, elektromanyetik kalkanlama etkinliği (ETKE), elektromanyetik uyumluluk (EMU) ve elektromanyetik girișim (EMG) gibi birçok ölçümün sağlıklı ve güvenilir bir şekilde yapılması, ölçüm ve test yapılan ortamın istenmeyen elektromanyetik girişim ve sinyallerden arındırılması ile mümkün olmaktadır. Bu nedenle bahsedilen testler ve ölçümler akredite laboratuvarlarda oldukça büyük ve yapılması maliyetli olan elektromanyetik yansitmasız odalarda ve yüksek bedellerle yapılmaktadır. Üniversiteler, araştırma kurumları ve üretim yapan küçük ölçekli işletmelerde bu tür ölçümlerin prototipleme ve üretim aşamasında birçok kez yapılmak zorunda olunması hem zaman kaybına neden olmakta hem de üretim maliyetlerini artırmaktadır. Bu çalışmada 700-3000 MHz bandında elektromanyetik test ve ölçümlerinde kullanılabilecek küçük boyutlu ve düşük maliyetli bir yansıtmasız kutu tasarımı anlatılmış, yapılan odanın performansı değerlendirilmiştir.

\section{A Radiofrequency Anechoic Box Design and Implementation for Electromagnetic Measurements}

Keywords
Electromagnetic
Shielding
Effectiveness,
Anechoic
Chamber,
High Frequency
Simulation

\section{Keywords}

Shielding

Effectiveness,

Simulation

\begin{abstract}
It is possible to achieve accurate and reliable measurements of electromagnetic fields, antenna parameters, electromagnetic shielding effectiveness (EMSE), electromagnetic compatibility (EMC) by eliminating the unwanted electromagnetic interference and signals from the measurement environment. Thus, aforementioned tests and measurements are held in anechoic chambers in laboratories with accreditation with high cost. The obligation of holding these kind of measurements many times in the process of prototyping and production both causes time loss and increase in the cost for the universities, research institutes and production facilities. In this study, the design of a small size, low cost anechoic box operating in the frequency range of 700-3000 $\mathrm{MHz}$ is explained and its performance is evaluated.
\end{abstract}




\section{Giriş}

Yüksek frekanslı devre ve cihazların günümüzde kullanımının oldukça yoğun olması ve kullanılan frekansların giderek yükselmesi, radyo frekans donanım tasarım ve üretimini yüksek getirili bir alan haline getirmiștir. Bu kadar çok radyo frekans ile çalıșan cihazların tasarımı ve gerçeklenmesi, cihazların birbirleri ile etkileșimi, oluşturdukları toplam elektromanyetik kirliliğin ölçülüp belirlenmesi başlı başına uygulama ve uzmanlık alanları olmuștur. Bu etkilerin belirlenmesi ise tasarım ve üretim aşamalarında birçok ölçüm ve testin yapılmasını gerektirmektedir.

Türk Standartları Enstitüsü'nün Avrupa Birliği'nin birçok standardını adapte etmesiyle Elektromanyetik Uyumluluk (EMU) da üreticiler için oldukça önemli bir konu haline gelmiştir [1]. Bu ölçümlerin akredite laboratuvarlarca yapılması gerekmektedir ve oldukça yüksek bedellerle yapılmaktadır. $\mathrm{Bu}$ da maliyet artışı olarak yansımaktadır. Oysaki nihai tasarım için bu ölçümler yapılmadan önce, tasarım ve ilk örnek aşamasında da yapılabilir olması, nihai tasarımın akredite laboratuvar testlerden bir kerede geçebilir olmasına yardımcı olabilir.

Üniversite ve araştırma merkezlerinde radyofrekans (RF) devre, anten gibi yüksek frekans donanımlarını tasarlayan ve bu konuda bilimsel çalışmalar yürütenler için de benzer problemler söz konusudur. Günümüzde itibarlı dergilerde mutlaka uygulama sonuçları hakemlerce istenmektedir. Yapılan uygulamaların matematiksel model ve bilgisayar benzetim sonuçlarına yaklaşabilmesi için ölçüm ve test yapılan sistemin ortamdan kaynaklanan istenmeyen girişimlerden arınmış olması oldukça önemlidir.

1970'li yıllarda RF ölçümleri açık saha ortamlarında yapılmaktaydı. RF yansitmasız odaların test ortamının dışarıdan gelen istenmeyen elektromanyetik girişimlerden ve test edilen veya testte kullanılan donanımların yaydıkları elektromanyetik alanların, ortamdaki engellerden yansımasıyla test sonuçlarını etkilemesinin engellenmesi istemiyle ortaya çlkmışlardır. Temel prensibi ölçüm düzeneğinin mükemmel iletken bir ortamın içine alınarak ortam dışından gelebilecek istenmeyen girişimlerin engellenmesi ve mükemmel iletkenle sınırlandırılmış iç ortamın, odanın çalıșma frekansında uygun soğurma özelliği gösteren dielektrik ve/veya ferrit soğurucularla kaplanarak içerde oluşabilecek yansımaların en aza indirilmesine dayanır [2]. Kullanılmaya başlaması, 1970'lerde ilk RF ışıma yönergelerinin ortaya çıkmasıyla olsa da konuyla ilgili çalışmalar çok daha önce başlamıștır [3]. RF yansıtmasız odaların boyutları test yöntemine göre $21 \mathrm{~m}$ $\mathrm{x} 13,5 \mathrm{~m} \times 8,5 \mathrm{~m}$ gibi antenlerin $10 \mathrm{~m}$ 'den ölçüm alabileceği kadar büyük olabilmektedir [4]. Antenlerin 3m'den ölçüm alabileceği odalar büyüklükleri ise 7m'ye ulaşabilmektedir [5]. Bu büyüklükte bir RF yansıtmasız odada 150 kHz'den 18 GHz'e kadar ölçümler yapılabilir. Odaların boyutlarının büyüklüğü ve maliyeti, daha o yıllarda daha küçük boyutlu ve düşük maliyetli muadillerinin olup olamayacağı tartışmasını başlatmıştır. Hutchinson ve Lazarewicz, firlatma rampasındaki bir yörünge radarının L-bandında testi için küçük ve düşük maliyetli bir RF yansıtmasız oda önermiş ve her ne kadar en hassas ölçümlerin büyük bir odada alınabileceğini söylese de ön ölçümler için böyle küçük boyutlu bir odanın da yeterli olacağını belirtmiştir [6]. Lirthioir ve Gavin 1988'de 120 cm x $180 \mathrm{~cm}$ boyutlarında, C bandından $\mathrm{Ku}$ bandına kadar çalışabilen taşınabilir bir yansıtmasız odayı raporlamıştır [7]. Icheln RF yansıtmasız odada dirençsel soğurucuların kullanılması durumunda 1,8 GHz frekansında, küçük boyutlu 

Uygulaması

antenlerin test ve ölçümlerinde kullanılabilecek minimum boyutu araștırmıș ve piramidal șekilli maksimum boyutu $91 \mathrm{~cm}$ olan soğurucular kullanıldığında, antenle soğurucu arasındaki mesafenin $10 \mathrm{~cm}$ altına düşmemesi durumunda, tüm yansıtmasız kutu boyutunun $250 \mathrm{~cm} \quad$ x $250 \mathrm{~cm}$ olabileceği sonucuna varmıștır [8]. Günümüz teknolojisiyle erişilebilir olan düzlemsel RF soğurucular ile bu boyutları daha da aşağıya çekmek mümkün olabilir. $\mathrm{Bu}$ çalışmada Dokuz Eylül Üniversitesi Elektrik - Elektronik Mühendisliği Bölümü Anten ve Mikrodalga Laboratuvarı'nda, 2013.KB.FEN.029 no'lu BAP destekli "Benzetim ve Ölçüm Yoluyla Elektromanyetik Kalkanlama Sistemleri Geliştirme ve Uygulama" isimli proje desteği ile tasarlanıp üretilmiş ve montajı tarafımızca gerçekleștirilmiş olan, 700 $\mathrm{MHz}$ - $3000 \mathrm{MHz}$ frekans bandında çalıștırılabilen, anten parametre ve kalkanlama etkinliği gibi testlerin yapılabildiği RF yansıtmasız kutunun tasarım ve gerçeklenmesi anlatılmış, kutunun performansı test edilmiștir. Kutunun boyutları 1,5m x $1 \mathrm{~m} \times 1 \mathrm{~m}$ 'dir. Kutunun içinde iki kat düzlemsel soğurucu kullanılmıștır.

\section{Materyal ve Metot}

\subsection{Genel Ortamda Oblik Dalga} Yansıması

Bütün elektromanyetik dalgalar Maxwell denklemlerini ve sınır koşullarını sağlar. Bu denklemler elektriksel özelliklerini ve dalga davranışını birbirine bağlar [9]. Doğrusal, izotropik ve homojen ortamlarda ilerleyen bir elektromanyetik dalganın, Şekil 1'deki gibi elektriksel özellikleri farklı bir ortamla karşılaşması durumu bir yansıma oluşturur. Eğer dalga düzlemsel dalga ise ve sınır koşulları gereği iki ortamın elektriksel özellikleri ile yansıyan ve geçen dalgalar arasında bir ilişki kurulabilir [10].

$$
\begin{gathered}
\left|\boldsymbol{E}_{r}\right|=\left|\Gamma \boldsymbol{E}_{i}\right| \\
\left|\boldsymbol{E}_{t}\right|=\left|T \boldsymbol{E}_{i}\right| \\
\left|\boldsymbol{H}_{r}\right|=\left|-\Gamma \boldsymbol{H}_{i}\right| \\
\left|\boldsymbol{H}_{t}\right|=\left|T \boldsymbol{H}_{i}\right| \\
\Gamma=\frac{\eta_{2} \cos \theta_{i}-\eta_{1} \cos \theta_{t}}{\eta_{2} \cos \theta_{i}+\eta_{1} \cos \theta_{t}} \\
\mathrm{~T}=\frac{2 \eta_{2} \cos \theta_{i}}{\eta_{2} \cos \theta_{i}+\eta_{1} \cos \theta_{t}}
\end{gathered}
$$

Denklem (1-2)'de $\boldsymbol{E}$ karmaşık vektör elektrik alan şiddetini, Denklem (3-4)'de $\boldsymbol{H}$ karmaşık vektör manyetik alan şiddetini, Denklem (5)'de $\Gamma$ yansıma katsayısını, Denklem (6)'da T iletim katsayısını vermektedir. $\eta$ ise ait olduğu ortamın yalın empedansıdır ve Denklem (7) ile tanımlanır. $\mathrm{Bu}$ denklemde $\mu$ permeabiliteyi, ã Denklem (8) ile verilen yayılım sabitini göstermektedir.

$$
\begin{gathered}
\eta=\frac{j \omega \mu}{\gamma} \\
\gamma=\alpha+j \beta \\
=j \omega \sqrt{\mu \varepsilon} \sqrt{1-j \sigma / \omega \varepsilon}
\end{gathered}
$$

Denklem (8)'de $\alpha$ zayıflatma katsayısını, $\beta$ faz katsayısını, $\varepsilon$ dielektrik sabitini ve $\sigma$ iletkenliği göstermektedir. Eğer dalganın yayıldığı dielektrik kayıplı bir ortamsa dielektrik sabiti, manyetik kayıplı bir ortamsa permeabilite karmaşık büyüklükler olur. Denklem (8), Denklem (7)'de yerine konulursa yalın empedans Denklem (9)'daki gibi yeniden yazılabilir.

$$
\eta=\sqrt{\frac{\mu}{\varepsilon}} \frac{1}{\sqrt{1-j \sigma / \omega \varepsilon}}
$$

Eğer dalga ikinci ortama dik bir șekilde düșüyorsa Denklem (5) ve (6), Denklem 

Uygulaması

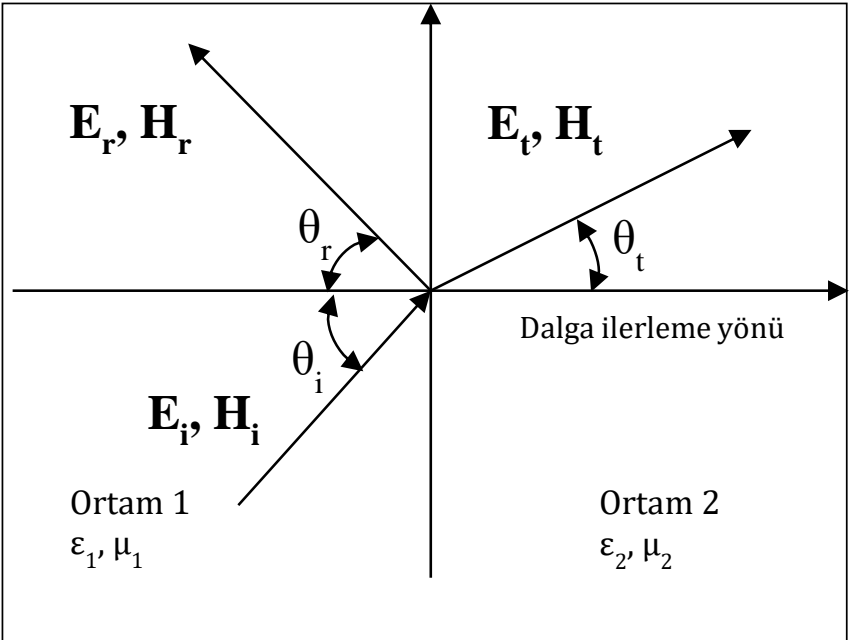

Şekil 1. Oblik düzlemsel dalganın elektriksel özellikleri farklı bir ortama düşmesi

(10) ve Denklem (11)'deki gibi basitleşmektedir.

$$
\begin{aligned}
& \Gamma=\frac{\eta_{2}-\eta_{1}}{\eta_{2}+\eta_{1}} \\
& \mathrm{~T}=\frac{2 \eta_{2}}{\eta_{2}+\eta_{1}}
\end{aligned}
$$

Özel durumlar düşünüldügünde, dalganın düştüğü ikinci ortam mükemmel iletkense $\sigma$ sonsuz olmakta ve ortamın yalın empedansı sıfır olmaktadır. Bu nedenle gelen dalga fazı terslenerek döner. Bu nedenle yapılan herhangi bir RF yansıtmasız odanın en dıșının çok iyi iletken ile kaplı olması, dışarıdan gelen herhangi bir dalganın tamamen yansıyarak dönmesine sebep olarak, içerideki test ortamının etkilenmesini engeller.

\subsection{RF Soğurucular}

$\mathrm{RF}$ yansıtmasız odaların dıșının tamamen iletken olması nedeniyle, iç alanda birçok yansıma oluşacaktır. $\mathrm{Bu}$ nedenle yansıtmasız odalarda RF soğurucu malzemeler kullanılır. $\mathrm{Bu}$ malzemeler genellikle esnek, yumuşak ve süngerimsi formdadır (Şekil 2). Kullanılan soğurucular kayıplı malzemelerden üretilirler. Bu kayıp, malzemeye ileten özellik verilmesi, dielektrik kayıplı malzeme seçilmesi ve hatta malzemenin ferrit ve karmaşık permeabiliteye sahip olması ile elde edilebilir. Kayıplı malzemeye düşen dalga içeri genliği düșerek nüfuz eder ve soğurucunun arkasındaki iletkene çarparak tekrar soğurucuya düşer. Genlik tekrar azalarak hava ortamına geri döner. Malzemenin büyüklüğü dalga boyu ile orantılıdır: Dalga boyu artınca soğurucunun boyutları artar, dalga boyu azalınca soğurucunun boyutları azalır.

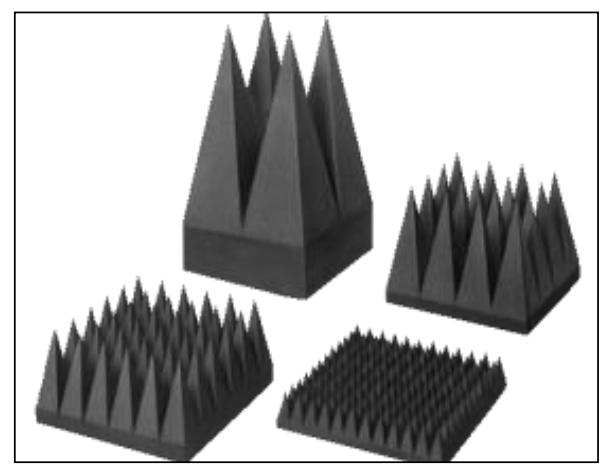

Şekil 2. Piramit geometriye sahip RF soğurucu 

Uygulaması

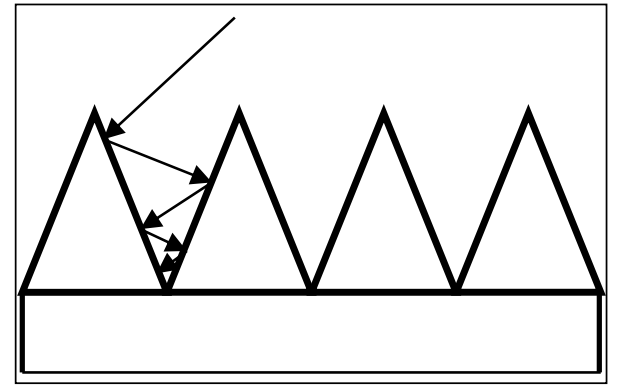

Şekil 3. Piramit geometrili bir RF soğurucuda çoklu yansıma

Soğurucular geometrik olarak ikiye ayrılır: Piramit soğurucular ve düzlemsel soğurucular. Piramit şekilli soğurucular malzemenin kayıplı olmasının yanı sıra şekli nedeniyle düşen dalganın birçok kez soğurucu içinde yansımasına neden olur (Şekil 3). Bu da soğurucunun etkinliğini artırır. Büyük boyutlara sahip RF yansıtmasız odalarda çoğunlukla bu çeşit soğurucular kullanılır çünkü bu soğurucuların soğurma oranları 60dB'ye kadar çıkabilir. Düzlemsel soğurucular [11] birden fazla katmandan oluşan, düzgün yapılı ve daha küçük boyutlu soğuruculardır (Şekil 4). Piramit soğuruculara göre daha düşük soğurma oranları vardır. Ama piramit soğuruculara göre daha az yer kapladıkları ve daha düşük maliyetli oldukları için bizim çalışmamıza daha uygundurlar.

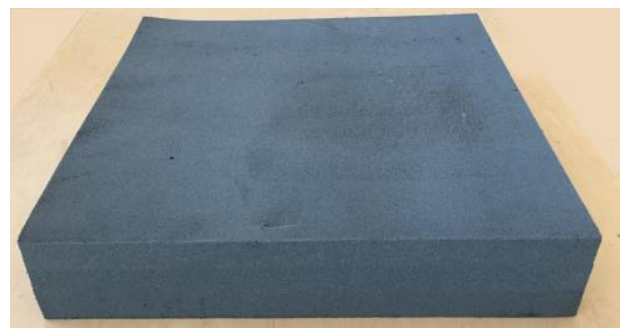

Şekil 4. Düzlemsel RF soğurucu

Kullanılan düzlemsel soğurucular tek veya çok katlı kayıplı sünger soğuruculardır. Temel olarak bu soğurucular, farklı dielektrik sabitine sahip homojen yapılı süngerlerin birbirleriyle birleștirilmesinden oluşur. $\mathrm{Bu}$ yapının en az miktarda alan yansıtması, yansıtılan alanın mümkün olduğunca gelen alanla ters fazda olması ve takıldığı yerdeki iletken yüzeyle karşılaşmadan önce geçirdiği alanı mümkün olduğunca zayıflatmaya uğratması beklenir [12]. Tablo 1'de ETSLingdren firmasından temin edilebilecek dört tip RF soğurucunun özellikleri ve soğurma performansları görülmektedir. $\mathrm{Bu}$ çizelge ve şekillerden edinilen bilgi ile FL-4500 CL ile FL-1125 CL serisi düzlemsel soğurucular tasarladığımız RF kutu için seçilmiştir. Ne yazık ki, soğurucularda kullanılan malzeme bilgisi firmalarca paylaşılmadığından, kutunun herhangi bir yüksek frekans benzetimi programı ile benzetiminin yapılması mümkün olmamaktadır. Öncelikle soğurucuların dielektrik sabiti, iletkenlik ve permeabilitelerinin tespit edilmesi gerekmektedir.

Seçilen soğurucuların elektromanyetik kalkanlama etkinliklerinin ölçümü Şekil 5 'de görülmektedir. En kalın soğurucu olan FL4500-CL soğurucusunun 900 MHz'den itibaren ortalama $10 \mathrm{~dB}$ soğurabildiği görülmüștür. Ancak bu performans $2200 \quad$ MHz'den itibaren azalmaktadır. $2200 \mathrm{MHz}$ üstündeki frekanslarda daha iyi soğurma sağlayabilmek için eklenen FL1125CL'nin tek başına soğurma performansı FL4500-CL'den düşük olmakla beraber, ikisinin birlikte kullanımı 900-2200 MHz bandına ortalama $10 \mathrm{~dB}$ daha soğurma artışı sağlamıştır. 2200 MHz'den sonra tek blok soğurucu kullanımına göre ortalama $4 \mathrm{~dB}$ soğurma artışı sağlamıştır.

\subsection{Kutunun Boyutlarının}

\section{Belirlenmesi}

Kalkanlama etkinliği, EMU, anten parametrelerinin belirlenmesi gibi ölçümlerin doğru bir şekilde yapılabilmesi için yayılımın düzlemsel dalga olarak gelmesi gerekmektedir. Antenden gelen elektromanyetik dalganın düzlemsel dalga olarak kabul edilebilmesi için antenle ölçülen nesne arasındaki uzaklığın en az antenin uzak alanı kadar 
olması gerekmektedir. Bundan daha ile ters orantılıymış gibi görülse de yakın mesafelerde hem antenlerin ışıma rezonans antenlerde antenin en büyük örüntüsü bozulmakta hem de reaktif boyutu dalga boyuyla doğru orantılı ışıma alanlarının içine girerek düzlemsel olduğundan, aslında uzak alan dalga boyu dalga kabulünün dışına çıkılmaktadır (Şekil 6). Anten uzak alanı Denklem (12) ile tanımlıdır.

$$
r>\frac{2 D^{2}}{\lambda}
$$

Denklem (12)'ye göre uzak alan antenin en büyük boyutuna ve dalga boyuna bağlıdır. Her ne kadar mesafe dalga boyu

azaldıkça küçülecektir. Geniş bant antenlerde ise belirli bir frekans bandında çalıșıldığından uzak alan en uzak mesafeyi veren frekans/dalga boyu kullanılarak hesaplanmalı ve dikkate alınmalıdır. Boşlukta dalga boyu $700 \mathrm{MHz}$ için 42,86 cm, $3000 \mathrm{MHz}$ için $10 \mathrm{~cm}$ 'dir. Sistemimizde kullandığımız antenin en büyük boyutu $17 \mathrm{~cm}$ 'dir. Bu boyuttaki bir anten için uzak alan $3000 \mathrm{MHz}$ 'de $58 \mathrm{~cm}$, 700 MHz'de $14 \mathrm{~cm}$ olarak hesaplanmıștır.

Tablo 1. ETS-Lindgren lamine düzlemsel soğurucu özellikleri [13]

\begin{tabular}{ccccccc}
\hline Model & Frekans & $\begin{array}{c}\text { Test } \\
\text { Frekansı }\end{array}$ & Kalınlık & $\begin{array}{c}\text { Taban } \\
\text { boyutu }\end{array}$ & Ağıllık & $\begin{array}{c}\text { Ortalama } \\
\text { Soğurma }\end{array}$ \\
FL-4500CL & $455 \mathrm{MHz}$ ve üstü & $800 \mathrm{MHz}$ & $11,4 \mathrm{~cm}$ & $61 \mathrm{~cm} \times 61 \mathrm{~cm}$ & $0,9 \mathrm{~kg}$ & $-25 \mathrm{~dB}$ \\
FL-2250CL & $940 \mathrm{MHz}$ ve üstü & $1700 \mathrm{MHz}$ & $5,7 \mathrm{~cm}$ & $61 \mathrm{~cm} \times 61 \mathrm{~cm}$ & $0,4 \mathrm{~kg}$ & $-30 \mathrm{~dB}$ \\
FL-1125CL & $2,4 \mathrm{GHz}$ ve üstü & $3000 \mathrm{MHz}$ & $2,9 \mathrm{~cm}$ & $61 \mathrm{~cm} \times 61 \mathrm{~cm}$ & $0,2 \mathrm{~kg}$ & $-20 \mathrm{~dB}$ \\
FL-0375CL & $7,5 \mathrm{GHz}$ ve üstü & $12 \mathrm{GHz}$ & $1 \mathrm{~cm}$ & $61 \mathrm{~cm} \times 61 \mathrm{~cm}$ & $0,1 \mathrm{~kg}$ & $-15 \mathrm{~dB}$ \\
\hline
\end{tabular}

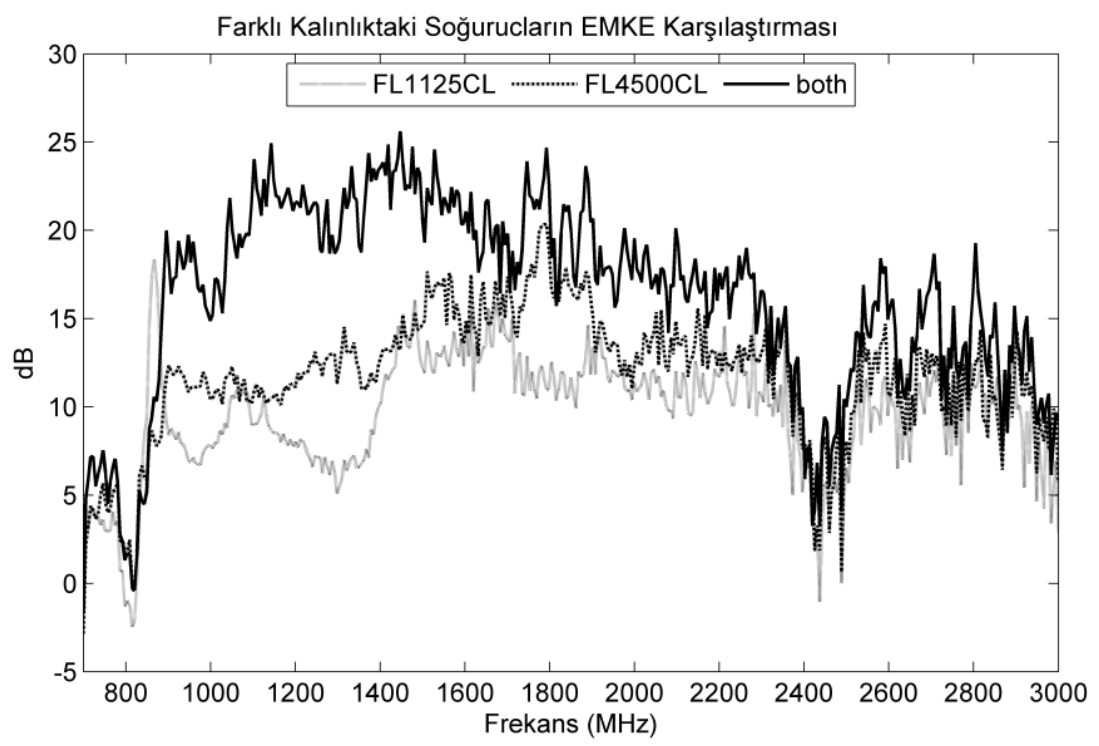

Şekil 5. Düzlemsel soğurucuların EMKE değerleri 


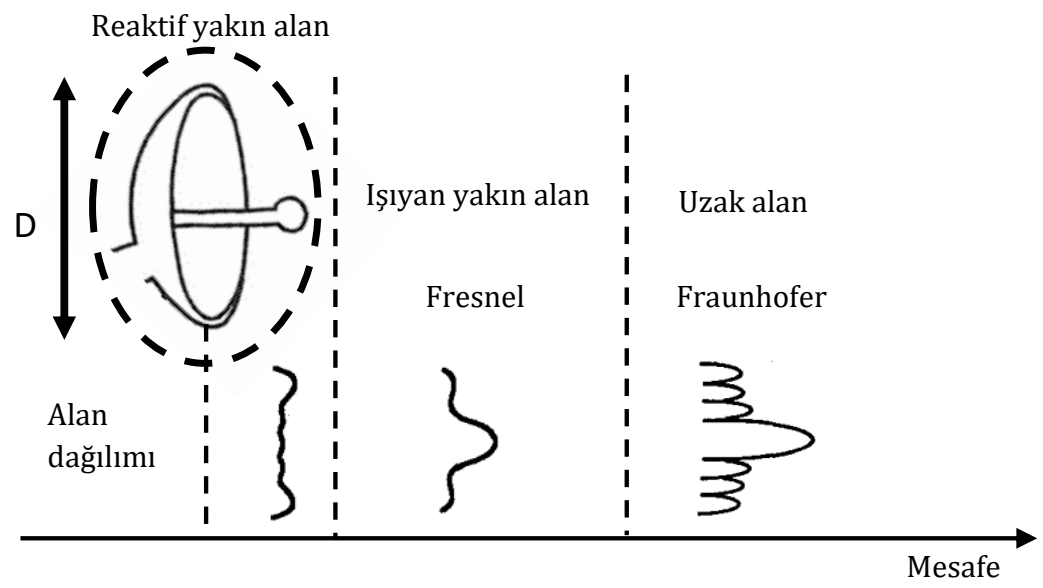

Şekil 6. Anten ışıma örüntüsünün mesafe ile değişimi [14]

İki anten arasındaki mesafe belirlenen $58 \mathrm{~cm}$ uzak alan için en az $116 \mathrm{~cm}$ olmalıdır. Seçilen soğurucuların kalınlıkları da hesaba katıldığında kutunun yataydaki uzunluğunun $1.5 \mathrm{~m}$ olmasına karar verilmiştir. Kutunun nihai boyutları $1 \mathrm{~m} \quad \mathrm{x} \quad 1.5 \mathrm{~m}$ x1m olarak belirlenmiștir (Şekil 7). Şekil 8' de RF yansitmasiz kutunun nihai hali görülmektedir. Kutunun kapakları iletken contalarla kaplanarak RF sızıntı ihtimali en aza indirilmiştir.

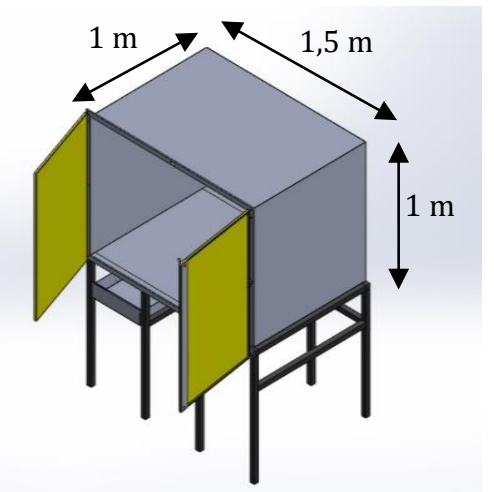

Şekil 7. RF yansıtmasız kutu nihai boyutları

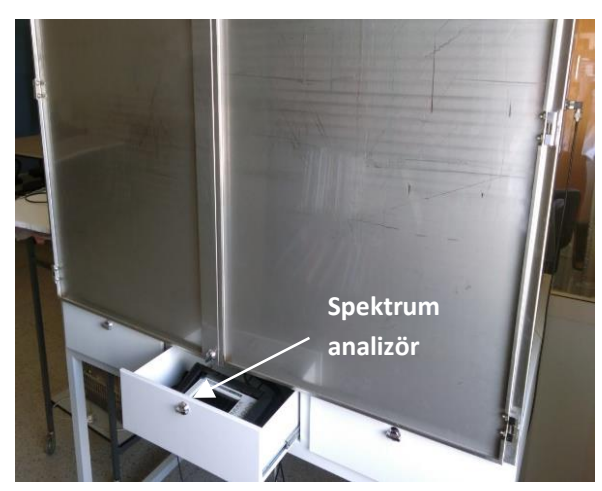

(a)

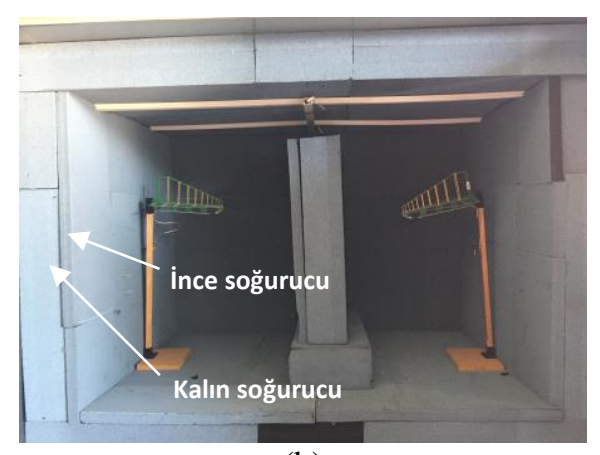

(b)

Şekil 8. Yansıtmasız RF kutunun (a) kapalı, (b) açık görünümü

\section{Yansitmasız Kutu Performansının Değerlendirilmesi}

Yapımı tamamlanan RF yansitmasız kutunun performans ölçümleri Dokuz 
Eylül Üniversitesi Elektrik - Elektronik Mühendisliği Mikrodalga ve Anten Laboratuvarında yapılmıştır. İlk olarak, Gigahertz Solutions firmasınca üretilmiş olan ve 700-3000 MHz frekans bandında çalışan log-periyodik antenin yansıma katsayısı odada ölçülmüştür. Maalesef antenin üretici firma tarafından verilen bir özellik verisi elimizde bulunmamaktadır. Antenin $\mathrm{S}_{11}$ parametresinin, istenilen çalışma frekansı boyunca 10dB'nin altında olması beklenmektedir (Şekil 9). Bu aynı zamanda gerilim duran dalga oranının da aynı frekans bandı boyunca 2'nin altında olması demektir (Şekil 10). Kullanılan anten ilgili çalışma bandının büyük bir çoğunluğunda her iki şartı da sağlamaktadır. Sadece 2862-2871 MHz arasındaki bir bölgede gerilim durağan dalga oranı ortalama 2,03 olarak ölçülmüştür.

\section{Tartışma ve Sonuç}

Bu çalışmada alanda uygulanan standart boyutlarda ölçüm yapan oldukça pahalı akredite ölçüm sistemlerindeki ölçümler öncesi, olası anormallikleri belirleyebilmek amaciyla kullanılabilecek, boyutları 1,5m x $1 \mathrm{~m}$ x $1 \mathrm{~m}$ olan, dışı paslanmaz çelik, içi düzlemsel lamine soğurucular ile kaplanmış olan RF yansıtmasız kutunun tasarımı anlatılmış, üretilen odanın içi tarafımızca kaplanarak gerekli kablo ve donanım bağlantıları yapılmıștır. Nihai durumun performans incelemesi gerçekleştirilmiştir. Tasarlanan RF yansitmasız kutu 700-3000 MHz frekans aralığında kullanılabilen, anten uzak alanı olarak belirlenen ölçülerde, küçük boyutlu ve ön ölçümler olarak oldukça düşük maliyetli olma özelliğini taşımaktadır.

Üretilen yansıtmasız oda ön izleme amaçlı EMU ölçümleri, elektromanyetik kalkanlama etkinliği ve anten parametreleri ölçümlerinde kullanılabilir. Ürün prototipleme aşamasında olan firmalar ve araştırma kurumlarınca, akredite bir laboratuvara nihai ürünü göndermeden önce, ürün hakkında fikir edinme amacıyla bu ölçümler yapılabilir. Bir sonraki aşamada antenlerin $360^{\circ}$ dönmelerini sağlayan döner tabla eklenmesiyle, antenlerin ışıma örüntülerinin çıkarılması da hedeflenmektedir.

Geliştirilen sistem, beraber kullanılan RF network analizör ve RF üreteç içeren spektrum analizör yardımı ile anten parametrelerinden yansıma katsayısı, iletim katsayısı, kazanç; soğurucu ve yansıtıcı yüzey, boya ve kumaş tipi ürünlerin iletim ve soğurma katsayıları, kalkanlama etkinliği ile çeșitli aktif devre ve cihazların EMU ve EMG testleri için ilgili frekans bandında rahatlıkla kullanılabilir. Sistemin çalışma bandını sinırlayan en önemli faktör anten boyutudur. 3 GHz'den daha yukarı frekanslara çıkıldıkça, anten boyutu önemli ölçüde küçüleceğinden, anten uzak alan mesafesi kisalacaktır. Bu nedenle sistemin üst bantlarda uygun antenlerle kullanılması mümkün olacaktır. Ancak $700 \mathrm{MHz}$ ve aşağı frekanslarda, daha küçük boyutlu bir anten yapılmadıkça, sistemin verimli çalışması mümkün olmayacaktır. $\mathrm{Bu}$ noktada spiral antenler gibi elektriksel olarak küçük antenler kullanılabilir. Bu noktada antenlerin çalışma frekansındaki ışıma örüntüleri dikkate alınmalıdır.

Kullanılan soğurucuların elektriksel özellikleri elde edilemediği için sistemin bilgisayarlı benzetimi yaplamamıştır. $\mathrm{Bu}$ özellikler bilinebildiği takdirde, antenler arasındaki mesafe böyle bir benzetim ile optimize edilebilir. İlgili soğurucu ve kalkanlama materyallerinin içerikleri ve boyut ve kalınlık gibi tasarım parametrelerinin elde edilmesine ve bu yolla uygulamaya en uygun kalkanlama yapısının oluşturulması ile ilgili çalışmalar benzetim yoluyla sürdürülmektedir. 


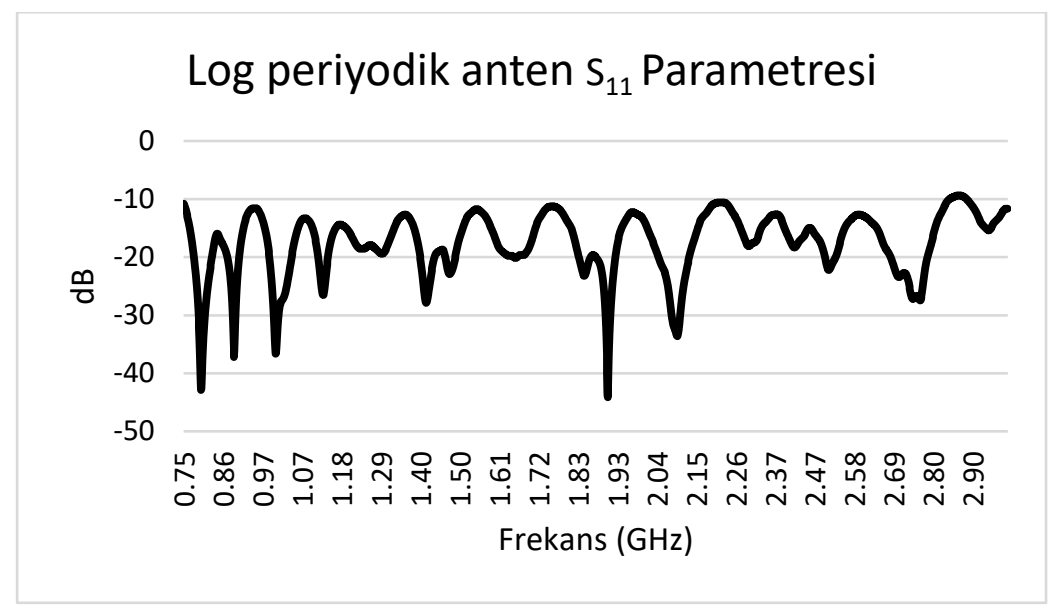

Şekil 9. Yansıtmasız odada Gigahertz Solutions anteninin bağlı olması durumunda $\mathrm{S}_{11}$ parametresi

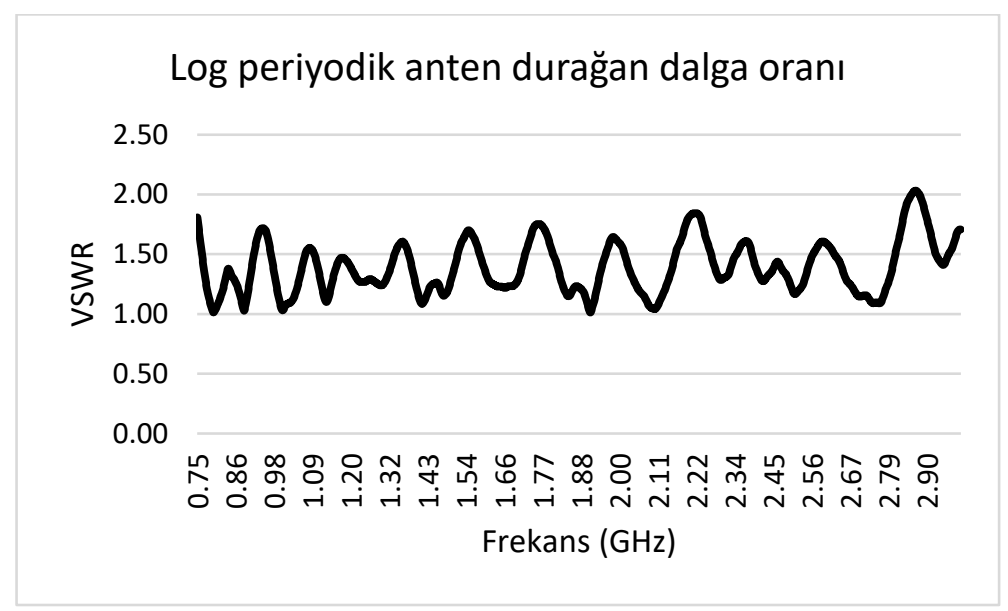

Şekil 10. RF Yansıtmasız Odada Voltaj Durağan Dalga Oranı

\section{Teşekkür}

$\mathrm{Bu}$ çalışma Dokuz Eylül Üniversitesi Bilimsel Araștırma Koordinasyonu'nun 2013.KB.FEN.029 kapsamında yapılmıştır.

Projeleri desteklediği sayll proje

\section{Kaynakça}

[1] Anonim, 2006.

TSE

Elektromanyetik Uyumluluk (EMU)

- TS EN 61000-6-2, Ankara.

[2] Cory, W.E., Dolle, W.C., Milstead, F.C. 1965. Standing Wave Reduction in an RFI Laboratory, Cilt 7, s.64-72.
DOI:

10.1109/ISEMC.1964.7565225

[3] Lawrance, B.F. 2005. Anechoic Chambers, Past and Present, Littleton. http://www.etslindgren.com/manuals/anechoic_c hambers_lawrence.pdf (Erişim Tarihi: 10.10.2015)

[4] NEC/TOKIN. 2002. Anechoic Chambers. http://www.tee.tokin.jp/eng/pdf/ ANECHOIC_CHAMBERS.pdf] (Erişim Tarihi: 10.10.2015) 
[5] Ishino, K. Hashimoto, Y. Okamurai M. Shizimizu, Y. 1991. Compact Anechoic Chamber for Immunity Test and EMO Noise Measurement. International Symposium on Electromagnetic Compatibility, 12 Temmuz - 16 Ağustos, 432-437.

[6] Hutchinson, F.W., Lazarewicz, A.J. 1963. A Portable Anechoic Chamber for PAD Use, IEEE Transactions on Aerospace, Cilt. 1, s. 46-50. DOI: 10.1109/TA.1963.4319364

[7] Lirthioir, J. Gavin, P. 1988. A Portable Miniature Anechoic Chamber. IEEE International Automatic Testing Conference, 4-6 Ekim 1988, 75-80.

[8] Icheln, C., Ollikainen, J., Vainikainen, P. 2001. Effects of RF Absorbers on Measurements of Small Antennas in Small Anechoic Chambers, IEEE Aerospace and Electronic Systems Magazine, Cilt 16, s.17-20. DOI: 10.1109/IMTC.1999.776748.

[9] Harrington, R.F. 2001. TimeHarmonic Electromagnetic Fields. A
Classic Reissue. IEEE Press. USA, 496s.

[10] Pozar, D.M. 2004. Microwave Engineering. 3rd edition. John Wiley \& Sons Inc. USA, 720s.

[11] ETS-Lindgren. 2014. Flat Laminate Absorber Specs. http://www.etslindgren.com/specs/FL-

FlatLaminateAbsorber (Erișim Tarihi: 25.11.2015)

[12] Celozzi, S., Araneo, R.,Lovat, G. 2008. Electormagnetic Shielding. John Wiley \& Sons. New Jersey, 375s.

[13] ETS-Lindgren. 2003. Microwave Absorber Selection Guide. http://www.etslindgren.com/pdf/absorber.pdf (Erişim Tarihi: 25.11.2015)

[14] Rahmat-Samii, Y., Williams, L.I., Yaccarino, R.G. 1995. The UCLA Bipolar Planar-Near-Field AntennaMeasurement and Diagnostic Range, IEEE Antennas and Propagation Magazine, Cilt 37, s.1635. DOI: $10.1109 / 74$. 